\title{
P-TEFb kinase is required for HIV Tat transcriptional activation in vivo and in vitro
}

\author{
Helena S.Y. Mancebo, ${ }^{1}$ Gary Lee, ${ }^{1}$ John Flygare, ${ }^{1}$ Joanne Tomassini, ${ }^{3}$ Percy Luu, ${ }^{1}$ Yuerong Zhu, $^{2}$ \\ Junmin Peng, ${ }^{2}$ Carol Blau, ${ }^{3}$ Daria Hazuda, ${ }^{3}$ David Price, $^{2}$ and Osvaldo Flores ${ }^{1,4}$ \\ ${ }^{1}$ Tularik, Inc., South San Francisco, California 94080 USA; ²Department of Biochemistry, University of Iowa, Iowa City, \\ Iowa 52242 USA; ${ }^{3}$ Department of Antiviral Research, Merck Research Laboratories, West Point, Pennsylvania 19446 USA
}

\begin{abstract}
To identify novel inhibitors of transcriptional activation by the HIV Tat protein, we used a combination of in vitro and in vivo Tat-dependent transcription assays to screen $>100,000$ compounds. All compounds identified blocked Tat-dependent stimulation of transcriptional elongation. Analysis of a panel of structurally diverse inhibitors indicated that their target is the human homolog of D rosophila positive transcription elongation factor $b$ (P-TEFb). Loss of Tat transactivation in extracts depleted of the kinase subunit of human P-TEFb, PITALRE, was reversed by addition of partially purified human P-TEFb. Transfection experiments with wild-type or kinase knockout PITALRE demonstrated that P-TEFb is required for Tat function. Our results suggest that P-TEFb represents an attractive target for the development of novel HIV therapeutics.
\end{abstract}

[Key Words: P-TEFb kinase; HIV Tat protein; transcriptional activation; kinase inhibitors]

Received August 1, 1997; revised version accepted August 22, 1997.

The Tat protein encoded by the human immunodeficiency virus (HIV) is essential for viral replication and therefore represents an attractive target for the development of novel therapeutics for the treatment of HIV infections. Initially proposed to function in both transcription and translation, it is now clear that the major role of Tat during the viral life cycle is to activate viral gene expression at the level of transcription. Three cis-acting elements within the viral genome's long terminal repeat (LTR) are absolutely required for Tat-dependent activation of viral transcription in vivo and in vitro. These include the TATA box, a binding site for the transcription factor Sp1, and the transactivation response (TAR) element. The TAR element is recognized by Tat as a nascent RNA structure and is believed to have a critical role in recruiting $T$ at to the viral promoter within the LTR (for review, see Jones and Peterlin 1994).

Several lines of evidence suggest that transactivation of HIV transcription by Tat requires additional host celIular cofactors (for examples, see Marciniak et al. 1990; Newstein et al. 1990; Sheline et al. 1991; Winslow and Trono 1993; Zhou and Sharp 1995). Although a number of cellular proteins have been proposed to be Tat cofactors on the basis of their ability to bind to Tat or TAR, functional data illustrating their participation in Tat-dependent transcriptional activation is lacking. One of the strongest candidates for a Tat-specific cellular cofactor is

${ }^{4}$ Corresponding author.

E-MAIL Lalo@ ularik.com; FAX (415) 829-4400.
Tat-SF1, which was identified as a chromatographic fraction required for Tat transactivation in vitro (Zhou and Sharp 1995). A cDN A encoding a 140-kD phosphoprotein has been isolated and proposed to be responsible for Tat-SF1 activity (Zhou and Sharp 1996).

An important contribution to the understanding of Tat function derived from transcription run-on experiments that revealed the primary effect of $T$ at to be an increase in the processivity (i.e., elongation efficiency) of RNA polymerase II (Pol II) (Laspia et al. 1989, 1990; Feinberg et al. 1991). An additional observation linking $T$ at with the control of transcriptional el ongation is that Tat-dependent stimulation of elongation by Pol II is inhibited by the purine nucleoside anal og 5,6-dicl oro-1- $\beta$-D-ribofuranosylbenzimidazole (DRB) (M arciniak and Sharp 1991). DRB has long been recognized to be an inhibitor of transcriptional el ongation by Pol II both in vivo and in vitro. This conclusion is based on the observation that DRB reduces preferentially the synthesis of Iong mRNA transcripts and has a minimal effect on promoter-proximal transcripts (Fraser et al. 1979; Tamm and Kikuchi 1979; Laub et al. 1980; Tweeten and M olloy 1981; Chodosh et al. 1989). The finding that DRB can inhibit cellular kinases in vitro led to the assumption that cellular kinases mediate the biological activity of DRB (Zandomeni and Weinmann 1984; Zandomeni et al. 1986). Moreover, certain kinases have been proposed to be involved in transcriptional el ongation control by virtue of their sensitivity to DRB (Yankulov et al. 1996). However, these associations do not take into account that the biological 
activity of DRB might result from simultaneous interaction with multiple target proteins. Because DRB is a purine nucleoside analog, it can potentially interfere with any enzyme that uses purine nucleotides, as well as more than one cellular kinase. Correlative analyses aimed at the identification of candidate targets for a given drug requi re study of the effects of multiple related compounds on the activity of several potential target proteins.

A weal th of studies have suggested that phosphorylation of the carboxy-terminal domain (CTD) of the largest subunit of Pol II is a critical regulatory step in the modulation of elongation competence (Dahmus 1996). These important studies have led to the proposal of the following general model: The dephosphorylated form of Pol II (Pol IIa) is recruited to the transcriptional preinitiation complex, and subsequent phosphorylation of the CTD converts the enzyme to an elongation-competent form (Pol IIo). A requirement of this model is that CTD-specific protein kinases are involved in elongation control. This model predicts further that a DRB-sensitive, CTDspecific protein kinase is involved in the regulation of transcriptional elongation by HIV Tat. This prediction has been strengthened by the observation that cellular kinases associate with the activation domain of Tat in vivo and in vitro (Herrmann and Rice 1993, 1995; Y ang et al. 1996).

We showed previously that the Drosophila positive transcription elongation factor $b$ (P-TEFb) contains a DRB-sensitive CTD-kinase activity ( $M$ arshall et al. 1996). In an accompanying paper (Zhu et al., this issue) we report that PITALRE, a member of the CDC2 family of protein kinases, is the catalytic subunit of human P-TEFb and associates with the activation domain of Tat. Here, we summarize the results of a random screen designed to identify chemical inhibitors of Tat-dependent activation of transcription in vitro. Remarkably, al I of the Tat-selective inhibitors identified in this screen were protein kinase inhibitors, including DRB and other structurally related compounds. These inhibitors blocked Tat-activated transcriptional elongation in vitro and Tat transactivation in cell culture. The results of our in vitro kinase assays, in vitro transcription experiments, and transient transfections all support the conclusion that $\mathrm{P}-\mathrm{TEFb}$ is required for Tat-mediated potentiation of transcriptional elongation.

\section{Results}

Development of a Tat-dependent in vitro transcription assay

Although several Tat inhibitors have been described (M arciniak and Sharp 1991; H su et al. 1992; M ichne et al . 1995), we were interested in identifying more potent and selective inhibitors of $T$ at, which would be useful in the elucidation of Tat function. To this end, we devel oped an in vitro transcription assay that recapitulates TAR-dependent Tat transactivation. We then used this assay to screen a library of pure chemicals for inhibitors of Tat function.
The in vitro transcription reactions consisted of purified Pol II, general transcription factors, a small amount of HeLa nuclear extract (that supplied cofactors necessary for efficient Tat activation), and an HIV LTR-promoter derivative fused to a G-less cassette as the template (Fig. 1A). Optimal Tat transactivation required LTR promoter sequences from -80 to +59 relative to the start site of transcription, as well as an intact TAR element. Removal of the Spl-binding sites in the LTR or mutations that disrupt either the bulge or loop domains of TAR abolished the Tat response (Fig. 1B). Dose-response experiments indicate that maximal activation was achieved at a Tat concentration of $25 \mathrm{~nm}$ and a 10:1 molar ratio of Tat protein to DNA template (Fig. 1C).

Different types of kinase inhibitors can function as selective antagonists of Tat activation of transcription in vitro

The assay described above was used in a random screen of a library of pure chemicals arranged in pools that each contained an average of 10 compounds. A complete description of the results of our screen will be published elsewhere. After screening 10,000 pooled samples (a total of $\sim 100,000$ compounds), 14 individual compounds were identified that inhibited selectively $T$ at-dependent transcriptional activation in vitro. These 14 compounds did not inhibit a control assay that measured transcriptional activation by immediate-early protein 2 (IE2 or IE86), a potent in vivo and in vitro activator of human cytomegal ovirus (HCM V) gene expression (Klucher et al. 1993). In each case, the compound identified in the primary assay was a kinase inhibitor. Among these, we found DRB and related nucleosides, benzimidazoles, isoquinoline sulfonamides, flavonoids, and novel kinase inhibitors (see below). Additional compounds that block Tat function were identified subsequently by testing a collection of known kinase inhibitors and related compounds in the in vitro transcription assay.

The selectivity of the inhibitors identified in our screen was investigated further by analyzing their effect on LTR-directed basal transcription and in transcriptional activation assays dependent on the BZLF (or Zta) protein of Epstein-Barr virus and the chimeric transcriptional activator Gal4-VP16 (Fig. 2). Transcription reactions supplemented with these factors were activated 5to 14-fold over basal transcription levels (Fig. 2A). Transcription conditions were identical in each case except for the activator protein and the DNA template. The LTR-basal conditions presumably measured Spl-dependent transcription, as judged from the dramatic reduction in product generation on deletion of the Spl-binding sites in the HIV LTR (Fig. 1B). The results of dose-re sponse experiments for three structurally unrelated kinase inhibitors in transcription assays with five different activators are shown in Figure 2B. At the concentrations tested, each of the three compounds inhibited preferentially transcriptional activation by Tat. At 10 - to 50 -fold higher compound concentrations, inhibition of basal transcription and of transcription in the presence of ac- 


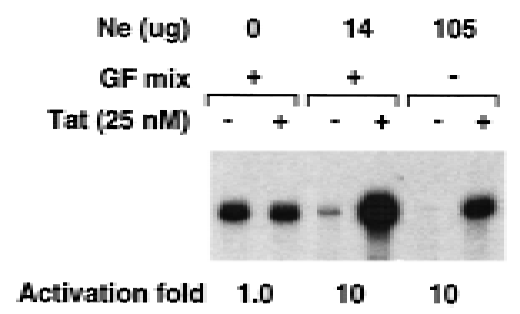

B Activation fold $\quad 1.0 \quad 10 \quad 10$

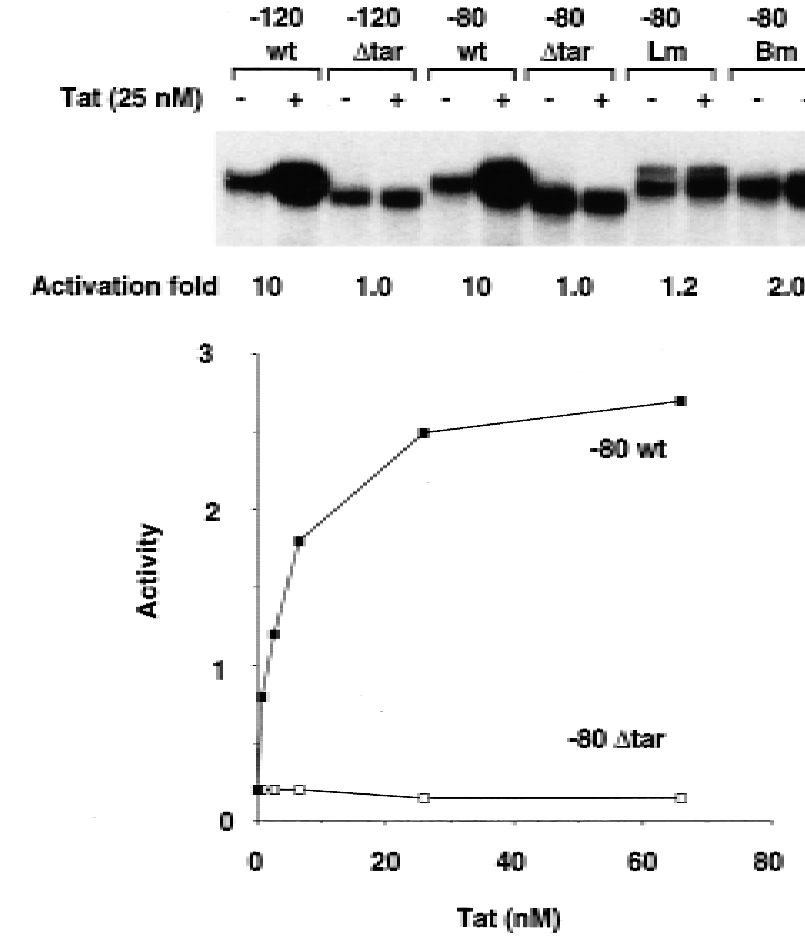

Figure 1. Tat-dependent in vitro transcription assay. Transcription reactions were as described in Materials and Methods and were reconstituted with purified Pol II, basal factors (GF mix), and a small amount of nuclear extract. Reaction products were quantitated with a Fuji Phosphorlmager. The $(\rightarrow$ and $(+)$ signs indicate reactions without or with $T$ at protein (25 nM), respectively. (A) The effect of increasing concentrations of nuclear extract on Tat transactivation. The fold activation for each reaction set (bracketed) is indicated at the bottom of the panel. The amount $(\mu \mathrm{g})$ of Hela nuclear extract ( $\mathrm{Ne}$ ) added to the reactions is also indicated. (B) Optimal Tat transactivation requires an intact TAR element and HIV LTR promoter sequences from -80 to -40 , relative to the start site of transcription. Brackets group sets of reactions minus $(-)$ and plus ( + ) Tat according to the LTR promoter derivative used as the DNA template. (wt) Wild-type TAR sequences; ( $\triangle T A R)$ del etion of TAR; (Lm) loop mutant; (Bm) bulge mutant. (C) The effect of increasing Tat concentrations on Tat-dependent transcription from either a wild-type or TAR-deleted -80 LTR promoter. Tat was added at $0.7,2.8,7,28$, and 66 $\mathrm{nm}$. tivators other than Tat was also observed (data not shown). Inhibition of transcription at these higher concentrations may result from inhibition of kinases or of another ATP-dependent process required for basal transcription.

Different structural classes of kinase inhibitors block Tat-dependent transcription elongation

The identification of DRB in a random screen for inhibitors of in vitro Tat-dependent transcription was not unexpected, as DRB had been shown previously to function as a Tat inhibitor in vitro (Marciniak and Sharp 1991). However, there were two surprising aspects of our screening results (1) after random screening of a large number of chemicals, only kinase inhibitors were identified as Tat-sel ective antagonists, and (2) kinase inhibitors structural ly unrelated to DRB were found to inhibit Tat activation. To address whether these inhibitors blocked specifically Tat-dependent stimulation of transcriptional elongation, we performed RN ase protection assays with probes that distinguished between promoter-proximal and promoter-distal transcripts (Fig. 3A). In vitro transcription reactions were assembled as de- scribed above and treated with either TRB, T276339, or $\mathrm{H} 7$. All of the compounds inhibited selectively the synthesis of Tat-dependent transcripts elongated to +1782 nucleotides, but had a minimal effect on the synthesis of promoter-proximal transcripts (Fig. 3A,B). These results confirm that Tat stimulates elongation in our in vitro system and that compounds other than DRB can function as potent antagonist of Tat-dependent transcription elongation in vitro. Similar experiments indicated that the inhibitors described in this study also inhibit Tatdependent transcriptional el ongation in intact cells (data not shown). From these results, we conclude that kinase inhibitors other than DRB can interfere with the ability of Tat to facilitate transcriptional elongation by Pol II both in vitro and in vivo.

\section{Kinase inhibitors also antagonize Tat function in} intact cells

It was important to investigate whether the inhibitors identified in vitro al so bl ocked Tat function in intact cell assays. To this end, we tested in cell culture a panel of compounds that included members of four different classes of kinase inhibitors, including ribofuranosyl 
Mancebo et al.

A

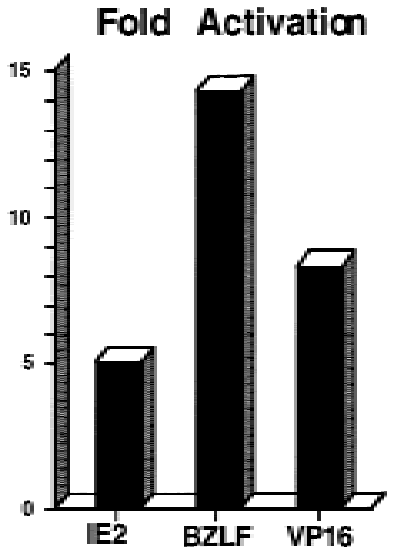

B
$3 X$ IE2-BS

$2 X$ BZLF-BS

5X GAL4-BS
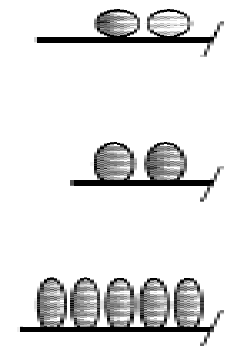

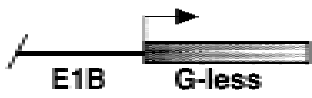

TRB

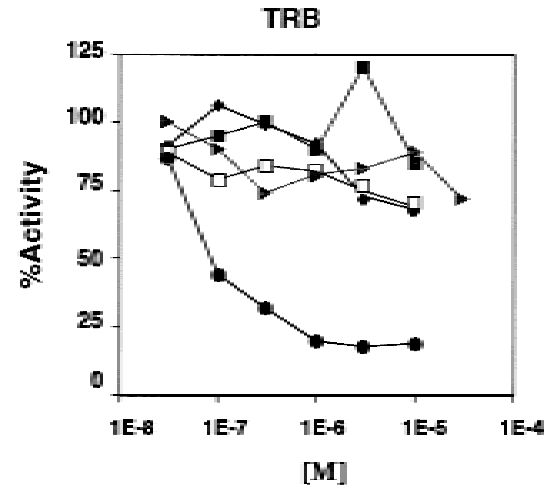

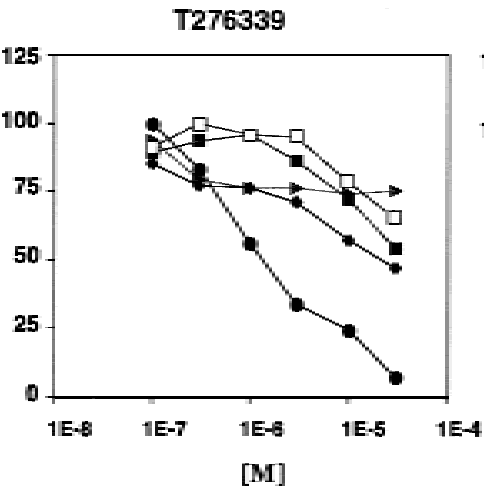

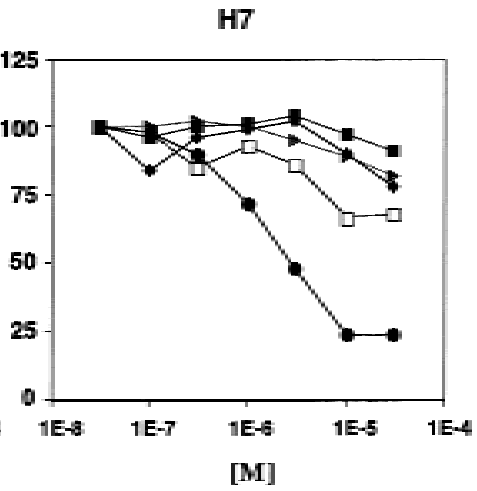

Figure 2. Selective inhibition of Tat activation in vitro by various types of kinase inhibitors. (A) A schematic representation of the DNA templates used to measure transcriptional activation by HCMV IE2, BZLF, and GAL4-VP16 proteins is shown. The fold induction attained in response to these proteins is indicated by the bar graph. (B) The effects of TRB, T276339, and H7 on various transcription assays. Transcription reactions were as described $M$ aterials and $M$ ethods and were quantitated with a Phosphorlmager.

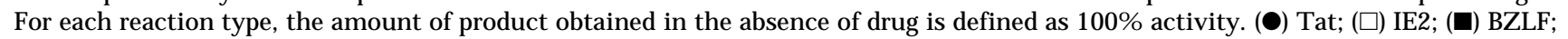
$(\diamond)$ GAL4-VP16; ( $\mathbf{\Delta})$ LTR-basal.

benzimidazoles, benzimidazoles, isoquinoline sulfonamides, and an oxazole, which is a novel kinase inhibitor discovered in our screen (Fig. 4). The 11 compounds included in this panel were either potent, weak, or inactive in vitro (Table 1), and the structure of each compound is shown in Figure 4. We measured their effects on Tatdependent transcriptional activation in cell culture by transient transfection of a Tat expression vector into a Jurkat cell line that contained a stably integrated HIV-1 provi rus adjacent to a luciferase reporter gene (see $M$ aterials and M ethods). To assess the specificity of the 11 compounds in cell culture, we performed two additional assays. First, we measured the effect of each compound on activated transcription in a Jurkat cell line that had been stably transfected with a HCMV enhancer-luciferase reporter construct. Second, we tested each of the 11 compounds in a cell prol iferation assay desi gned to measure general toxicity (see Materials and M ethods). The amount of compound required to attain $50 \%$ inhibition (IC-50) in each assay was determined with dose-response experiments over a wide range of compound concentrations.
As shown in Table 1, we observed a positive correlation between inhibition of Tat function in vitro and in cell culture. This result is remarkable, as differences in chemical stability and membrane permeability, which do not influence in vitro biochemical assays, can have profound effects on the biol ogical activity of a compound in cell culture. The ability of each compound to inhibit Tat activation in cell culture was directly proportional to the potency exhibited in vitro (Table 1). However, the apparent potency of the inhibitor in cell culture was approxi mately one-tenth of that observed in vitro. This difference likely reflects the fact that these compounds function as competitive inhibitors of ATP, and that the estimated intracel lular ATP concentration is at least 10 times higher than the ATP concentration used in the in vitro transcription assay.

The inhibition of Tat function in cell culture also appeared to be selective, as the concentration of compound required to inhibit Tat transactivation was significantly lower than that required to inhibit transcription driven by the HCM V enhancer (Table 1). In addition, the concentration of compound required to inhibit the HCMV 

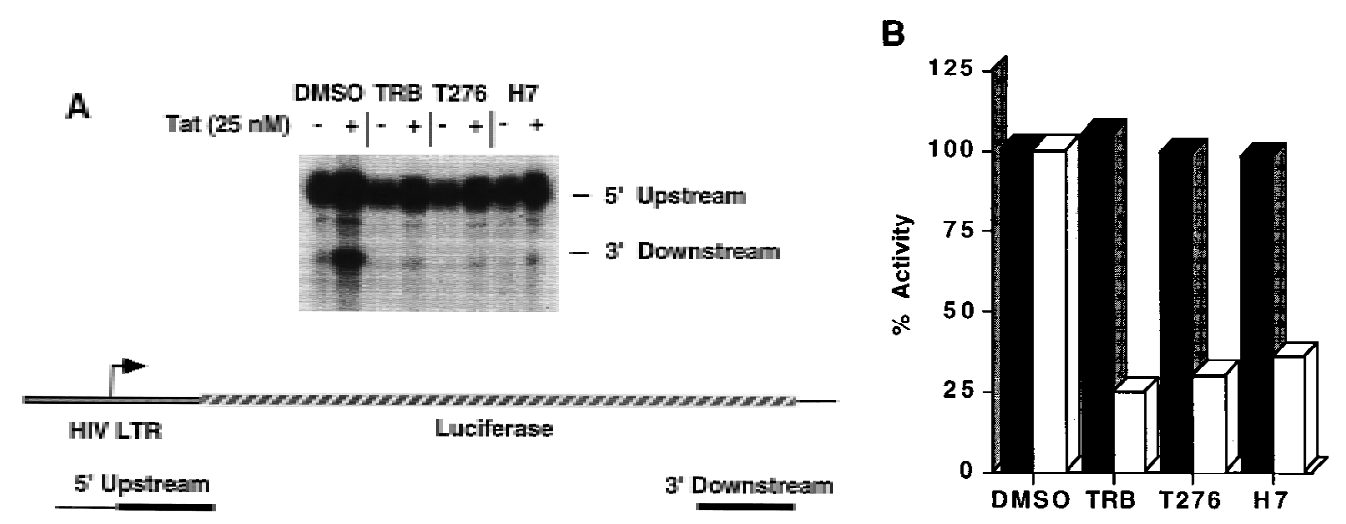

Figure 3. Sel ective inhibition of Tat-mediated potentiation of transcription el ongation in vitro and in vivo by various types of kinase inhibitors. Lanes label ed $(-)$ and $(+)$ refer to experiments performed in the presence or absence of Tat, respectively. (A) Use of RN ase protection to assess the effects of kinase inhibitors on the production of short and long mRNA transcripts. RN ase protection and transcription reactions were performed as described in $M$ aterials and $M$ ethods. Transcription reactions were reconstituted with the HIV LTR promoter fused to a luciferase reporter gene so that the same probes could be used to measure reaction products from in vitro and in vivo experiments. A schematic representation of the DN A template and the RN A probes is shown. The thin line in the 5' probe denotes LTR promoter sequences that are not protected by accurately initiated transcripts. TRB (1 $\mu \mathrm{M}), \mathrm{T} 276339(10 \mu \mathrm{M}), \mathrm{H} 7(10 \mu \mathrm{M})$, or DMSO solvent were added to reactions as indicated at the top. The mobility of products protected by the $5^{\prime}$ and $3^{\prime}$ probes in $6 \%$ polyacrylamide sequencing gels is indicated at the right. (B) Quantitation of products generated in the experiments in A. Values obtained in the absence of drug are defined as $100 \%$ activity. (四 $5^{\prime}$ transcript; ( $\square$ ) 3' transcript.

enhancer was similar to the concentration at which celIular toxicity was observed (Table 1). This result suggests strongly that inhibition of the HCMV enhancer is a result of nonspecific cellular toxicity. It may be that the observed toxicity arose from the inhibition of multiple kinases involved in various cellular processes. It is al so possible that the kinase required for Tat function is involved in the transcriptional regulation of multiple celIular genes. The latter possibility does not exclude the

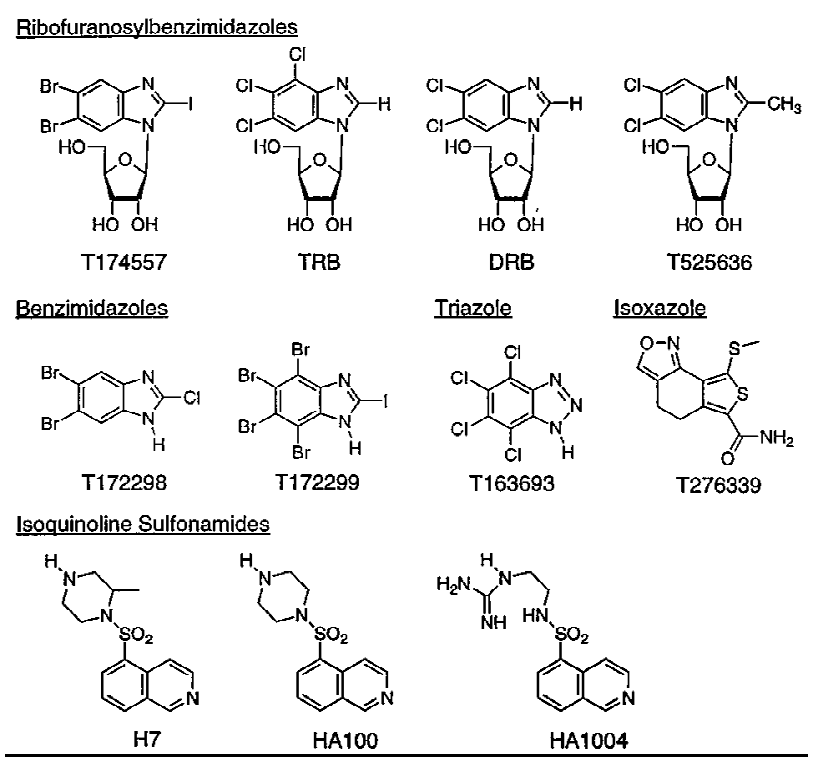

Figure 4. Structures of compounds analyzed in Tables 1 and 2. Compounds are grouped according to their structural class. The chemical name and source of each compound are described in Materials and M ethods. former, and toxicity might result from a combination of these effects. This series of in vivo experiments implies that the same cellular kinase is required for Tat activation in vitro and in intact cells.

Human P-TEFb kinase activity is abolished by kinase inhibitors that block Tat function

The finding that multiple, structurally diverse kinase in-

Table 1. Kinase inhibitors block Tat-dependent transcriptional activation both in vitro and in cell culture

\begin{tabular}{|c|c|c|c|c|c|}
\hline \multirow[b]{3}{*}{ Compound } & \multicolumn{5}{|c|}{ IC-50 ( $\mu \mathrm{M})$} \\
\hline & \multicolumn{2}{|c|}{ in vitro } & \multicolumn{2}{|c|}{ cell culture } & \multirow{2}{*}{$\frac{\text { cytotoxicit }}{\text { Jurkat }}$} \\
\hline & Tat & IE2 & Tat & $\mathrm{CMV}$ & \\
\hline T174557 & 0.1 & $>30$ & 5.0 & 30 & 30 \\
\hline TRB & 0.1 & $>30$ & 1.3 & 27 & 19 \\
\hline DRB & 0.5 & $>30$ & 5.0 & 91 & 56 \\
\hline T525636 & 15.0 & $>30$ & 100 & $>100$ & $>100$ \\
\hline T172298 & 0.2 & $>30$ & 10 & 65 & 65 \\
\hline T172299 & 4.0 & $>30$ & 65 & 100 & $>100$ \\
\hline T163693 & $>30$ & $>30$ & 55 & 60 & 75 \\
\hline T276339 & 1.0 & $>30$ & 1.0 & 50 & 12 \\
\hline $\mathrm{H} 7$ & 2.0 & $>30$ & 9.5 & 100 & 63 \\
\hline HA 100 & 5.0 & $>30$ & 6.0 & 90 & 55 \\
\hline HA 1004 & $>30$ & $>30$ & $>100$ & $>100$ & $>100$ \\
\hline
\end{tabular}

The compound concentration required to attain $50 \%$ inhibition in each assay (IC-50) was deciphered by interpolation of inhibitory curves generated from a series of experiments performed at no less than six different concentrations of compound. The IC50 values represent an average of three experiments. All assays of Tat and IE2 function were performed as described in M aterials and M ethods. 
hibitors abolish Tat transactivation both in vivo and in vitro suggests two possibilities: (1) There are multiple kinases that participate in the control of transcriptional elongation from the HIV LTR, and different inhibitors target different kinases, or (2) the various inhibitors all target the same enzyme. In an attempt to distinguish between these two possibilities, we analyzed the effects of a collection of kinase inhibitors on cellular kinases that have been proposed to function in Pol II transcription. We developed in vitro protein kinase assays for human P-TEFb kinase, the IIH-associated kinase Cdk7/Cyclin H, p34/Cyclin B, casein kinase II (CKII), protein kinase $A$ (PKA), and protein kinase $C$ (PKC). We purchased p34/Cyclin B, CKII, and PKA from commercial sources, and purified the IIH complex as described previously (Flores et al. 1992). Human P-TEFb kinase was isolated by immunoprecipitation with antibodies to the PITALRE kinase subunit. This procedure depletes DRB sensitivity from HeLa cell extracts and yields pure, active kinase protein (see Zhu et al., this issue).

Dose-response experiments were performed with the various compounds in all six protein kinase assays, and an IC-50 was calculated for each kinase inhibitor (Table 2). Although the ATP and substrate concentrations were similar among the seven assays, and enzyme concentrations were within the linear ranges, the efficiency of phosphate transfer varied among the different kinase assays (data not shown). Therefore, the results shown in Table 2 can be used only to assess the qual itative activity of each compound on a given enzyme. In each case, the ability of an inhibitor to block P-TEFb kinase activity correlated with its ability to inhibit Tat activation in vitro; this perfect correlation between inhibition of Tat activation and kinase activity was not observed with any of the other kinases tested (T able 2). For example, the IIH kinase, CKII, PKA, and PKC were unaffected by several of the compounds that were potent inhibitors of Tat function. Similarly, al though the benzimidazoles and ribofuranosyl benzimidazoles inhibited CKII, this kinase was also inhibited by T 163693, a compound that had no effect on Tat transactivation (Table 2). These observations suggest that P-TEFb is the target kinase of the inhibitors that block $T$ at activation.

Human P-TEFb is required for Tat activation in vitro

To assess more directly the requirement of P-TEFb in Tat activation, we immunodepleted nuclear extracts with either antibodies to PITALRE or a control antibody and measured the ability of the treated extracts to support Tat transactivation in vitro. Transcription reactions that were reconstituted with a set of purified general transcription factors supported DRB-insensitive, basal transcription and were not responsive to Tat (Fig. 5C, lanes 1-4). These results are consistent with immunoblot assays showing that the HeLa cell-purified factors used in our in vitro transcription system (Pol II, IIA, IID, and $\mathrm{IIH}$ ) are devoid of anti-PITALRE cross-reacting material (data not shown). Addition of HeLa nuclear extracts that had been depleted with control antibodies restored both responsiveness to T at and DRB sensitivity, suggesting that one of the activities contributed by the nuclear extract is a protein kinase (Fig. 5C, lanes 5-8). In contrast, the extract depleted with antibodies against PITALRE did not restore transactivation by T at, suggesting that human $\mathrm{P}-\mathrm{TEFb}$ is required for Tat transactivation in vitro (Fig. 5C, lanes 9-12).

Western blot analyses indicated that immunodeple tion with PITALRE antibodies did not remove either components of the basal transcriptional apparatus (data not shown) or Cdk7, another CTD kinase that has been implicated in Tat activation, whereas greater than 95\% of PITALRE was removed by the immunodepletion experiment (Fig. 5D).

Table 2. Human P-TEFb kinase activity is abolished by kinase inhibitors that block Tat function

\begin{tabular}{|c|c|c|c|c|c|c|c|c|}
\hline & \multirow[b]{2}{*}{ Compound } & \multirow[b]{2}{*}{ Tat } & \multicolumn{6}{|c|}{ IC-50 ( $\mu \mathrm{m})$} \\
\hline & & & P-TEFb & $\mathrm{IIH}$ & p34 & CKII & PKA & PKC \\
\hline \multirow{4}{*}{ Ribofuranosyl benzimidazoles } & $\Gamma \mathrm{T} 174557$ & 0.1 & 0.6 & $>30$ & $>30$ & 0.1 & $>30$ & $>30$ \\
\hline & TRB & 0.1 & 1.0 & $>30$ & 5.0 & 1.0 & $>30$ & $>30$ \\
\hline & DRB & 0.5 & 3.0 & 10.0 & $>30$ & 20.0 & $>30$ & $>30$ \\
\hline & L T525636 & 15.0 & $>30$ & $>30$ & $>30$ & N.D. & $>30$ & $>30$ \\
\hline \multirow{2}{*}{ Benzimidazoles } & [ T172298 & 0.2 & 0.9 & 5.0 & 10.0 & 0.1 & $>30$ & $>30$ \\
\hline & L T 172299 & 4.0 & 2.0 & 20.0 & 0.5 & 20.0 & $>30$ & $>30$ \\
\hline Triazole & T163693 & $>30$ & $>30$ & $>30$ & $>30$ & 0.1 & $>30$ & $>30$ \\
\hline Isoxazole & T276339 & 1.0 & 4.0 & $>30$ & 1.0 & $>30$ & $>30$ & $>30$ \\
\hline \multirow{3}{*}{ Isoquinoline sulfonamide } & $\Gamma \mathrm{H} 7$ & 2.0 & 9.0 & 10.0 & $>30$ & $>30$ & 10.0 & 1.0 \\
\hline & HA 100 & 5.0 & 19.0 & $>30$ & $>30$ & $>30$ & 2.0 & 0.5 \\
\hline & L HA1004 & $>30$ & $>30$ & $>30$ & 20.0 & $>0$ & 2.0 & $>30$ \\
\hline
\end{tabular}

IC-50 values were determined as described in the footnote to Table 1 . The compounds are grouped according to their structural class and listed according to their potency as Tat inhibitors. The correlation between inhibition of Tat activation and P-TEFb kinase is clearly observed on comparison of IC-50 values of compounds within each structural class on Tat activation and various kinase assays. (N.D.) N ot determined. 


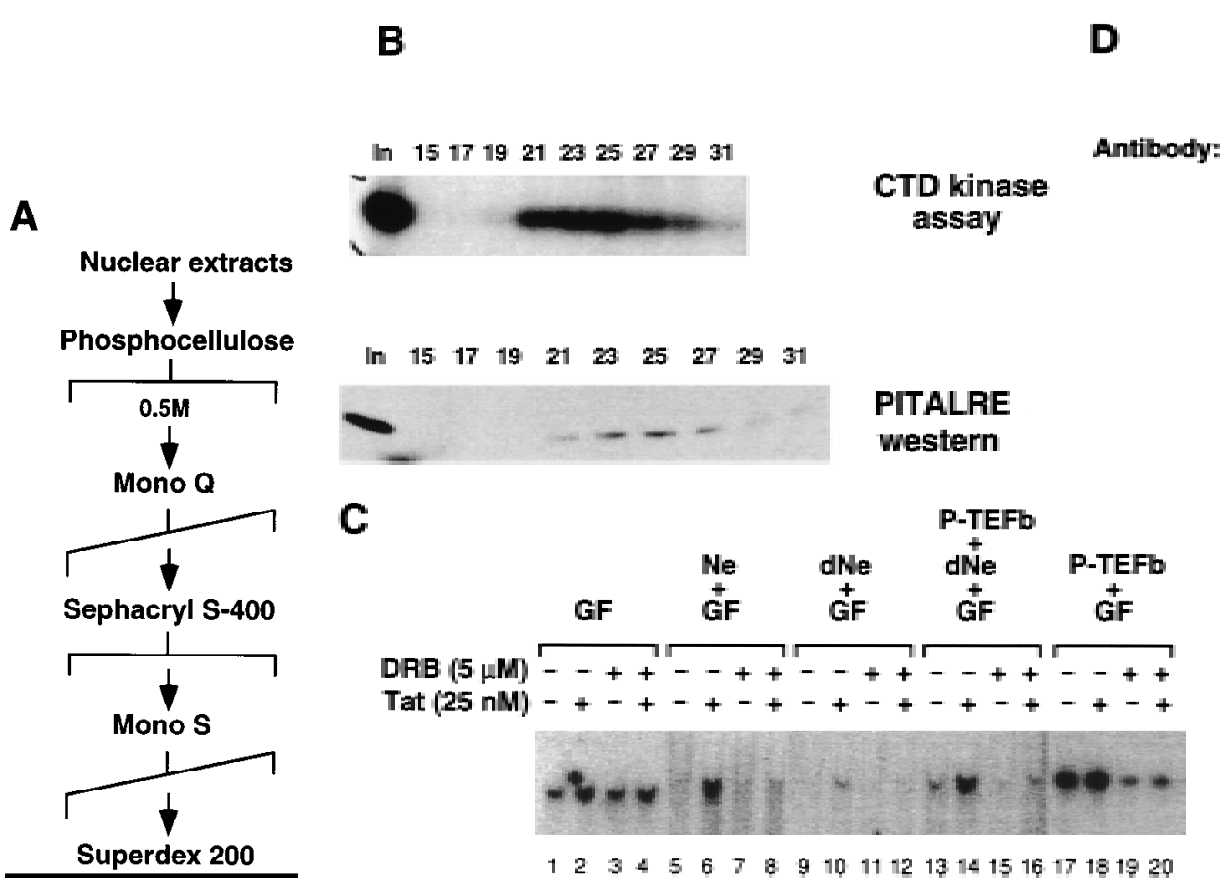

Figure 5. Requirement of P-TEFb for Tat transactivation in vitro. (A) Purification scheme for HeLa-derived P-TEFb. (B) CTD kinase assay (top) and PITALRE Western bl ot analysis (bottom) of Superdex 200 column fractions. Conditions for each assay were as described in Materials and M ethods. (C) HeLa cell-purified P-TEFb restores Tat transactivation to in vitro transcription reactions reconstituted with nuclear extracts that had been immunodepleted with antibodies against PITALRE. The presence $(+)$ or absence $(\rightarrow$ of Tat and/or DRB are indicated at the top. Reactions are grouped with brackets according to the factors added to complement Tat transactivation. (GF) General factors and Pol II; (N e) HeLa nuclear extracts (14 $\mu \mathrm{g})$ depleted with control antibodies; (dN E) HeLa nuclear extracts (14 $\mu \mathrm{g})$ depleted with antibodies to PITALRE; (P-TEFb) HeLa cell-purified P-TEFb. Lane numbers are indicated at the bottom. (D) Western blot analysis showing the depletion of PITALRE but not Cdk7 from HeLa nuclear extracts by the anti-PITALRE antibody.

Our attempts to restore Tat responsiveness to immunodepleted extracts with immunopurified P-TEFb were unsuccessful. Because recombinant human P-TEFb is not yet available, we purified human P-TEFb from HeLa cell nuclear extracts with the use of conventional chromatographic techniques. Although P-TEFb copurified with the IIH-Cdk7/cyclin $\mathrm{H}$ complex through the first two columns, these two kinase activites were separated after fractionation with Sephacryl S-400 and M ono S resins (data not shown). Human P-TEFb was purified extensively after five chromatographic procedures. Immunobl ot and CTD kinase assays performed on fractions from the final chromatographic step indicated that all of the detectable CTD kinase activity coeluted with P-TEFb (Fig. 5B).

Addition of the HeLa-purified P-TEFb fraction to transcription reactions that contained anti-PITALRE-depleted nuclear extracts restored both Tat-responsi veness and DRB sensitivity (Fig. 5C, lanes 13-16). Consistent with our observations in the Drosophila system, HeLa P-TEFb stimulated transcriptional elongation and conferred DRB sensitivity to in vitro transcription reactions that had been reconstituted with only basal initiation factors (Fig. 5C, lanes 17-20). The inability of purified HeLa P-TEFb to restore Tat responsiveness on its own suggests that additional factors present in the crude nuclear extract are required for Tat transactivation (see
Discussion). The results described above provide functional evidence in support of a role for P-TEFb in Tatmediated transcriptional activation in vitro.

A PITALRE kinase mutant has a dominant-negative effect on Tat transactivation

We next wished to test directly whether P-TEFb is required for transcriptional activation by $T$ at in vivo. To this end, we transiently transfected Jurkat and HeLa cells with an expression vector that contained a gene encoding either the wild-type PITALRE subunit or one that carried a mutation that abrogates its kinase activity. We then analyzed the effect of ectopic expression of either the wild-type or mutated PITALRE on Tat-independent and Tat-dependent transcriptional activation in the transfected cells. Tat-independent transcription was achieved either by omitting the Tat expression vector from the transfection assay (Fig. 6A,B) or by employing an LTR-luciferase reporter with deleted TAR sequence (data not shown). Western blot analyses indicated that both PITALRE derivatives were produced in similar amounts and were overexpressed with respect to the endogenous protein (data not shown). N either the wildtype nor the mutant PITALRE derivative affected Tatindependent transcription from the HIV LTR (Fig. 6A,B). Interestingly, expression of the wild-type PITALRE, but 
not the kinase mutant consi stently enhanced T at-dependent transcription in both cell types (Fig. 6A,B), suggesting that recruitment of P-TEFb kinase to the HIV LTR is dependent on Tat. This positive effect of wild-type PITALRE on the HIV LTR expression also depends on the intact TAR sequence in the promoter of the reporter gene (data not shown). M ore importantly, T at-dependent luciferase activity was inhibited on overexpression of mutant PITALRE in Jurkat and HeLa cells (Fig. 6A,B). Inhibition of Tat-dependent luciferase activity by mutant PITALRE was observed only under conditions that supported robust Tat transactivation. Jurkat cells supported the strongest Tat-dependent activation ( $>2500$ fold) and the most dramatic inhibition of Tat-mediated transcription by the mutant PITALRE kinase (Fig. 6A). HeLa cells supported intermediate levels of T at transactivation (an average of 50-fold), which were inhibited consistently $\sim 40 \%$ by the mutant PITALRE kinase. The dominant-negative effect of the mutated kinase subunit on Tat transactivation demonstrates that P-TEFb kinase activity is required for transcriptional activation by Tat in vivo.

\section{Discussion}

One of the striking aspects of this study is that we arrived at the conclusion that cellular kinases are crucial for Tat function using a unique, completely unbiased approach. The sensitivity of Tat-activated transcription to kinase inhibitors is reinforced dramatically with the finding that, after testing 100,000 different chemicals, all of the Tat-selective inhibitors identified in our screen were kinase inhibitors. The marked sensitivity of Tat transactivation to inhibitors of P-TEFb in vitro led us to the hypothesis that Tat is completely dependent on P-TEFb for stimulation of transcriptional elongation in vitro. In addition, we showed that stimulation of acti- vated transcription by certain other activators is not dependent on P-TEFb. This observation is consistent with the view that the primary effect of most transcriptional activators in vitro is to stimulate the rate of transcription initiation. Having at our disposal a collection of distinct kinase inhibitors that interfere with Tat function and block transcription elongation (Figs. 2 and 3), we were able to generate strong correlative evidence linking P-TEFb kinase to T at function. This linkage was reinforced by the observation that compounds that inhibit Tat transactivation also inhibit P-TEFb kinase activity (Table 2).

The first piece of direct functional evidence linking $\mathrm{P}-\mathrm{TEFb}$ to Tat transactivation came from immunodepletion experiments, which revealed that the removal of $\mathrm{P}$-TEFb from nucl ear extracts abrogates T at activation of transcription in vitro (Fig. 5C). It is important to re-emphasize that our in vitro transcription system contains a complete set of general factors capable of supporting vigorous basal transcription. The crude nuclear extract added to the transcription reaction contributes only the cofactors required for T at transactivation (Fig. 1). There fore, the loss of Tat transactivation on treatment of the extract with antibodies to PITALRE implies that cofactors required for $T$ at function were removed by the immunodepl etion process.

We have been unable to el ute active P-TEFb from the protein A-Sepharose beads, and resin-bound P-TEFb kinase does not restore Tat transactivation. However, addition of a HeLa cell-purified P-TEFb fraction restored Tat cofactor activity to the immunodepleted extracts. The CTD kinase activity that copurifies with P-TEFb is fully sensitive to P-TEFb inhibitors, indicating that $\mathrm{P}-\mathrm{TEFb}$ is the only CTD kinase present in this fraction. At this point, we cannot rule out the possibility that this chromatographic fraction contains additional factors that influence P-TEFb activity. However, this possibility does not in any way diminish the conclusion that
Figure 6. Participation of P-TEFb in Tat transactivation in intact cells. (A) Inhibition of Tat-dependent transactivation by overexpression of mutated PITALRE in Jurkat cells. All transfections were performed with a wild-type LTR-luciferase reporter with $(+)$ or without $(\rightarrow$ a Tat expression vector and without (-) or with wild-type (wt) or mutated (mt) PITALRE expression vectors as indicated. Luciferase values were normalized with respect to the luciferase activity obtained with the reporter plasmid al one. In each case the luciferase values represent the average of three independent experiments. For each experiment, luciferase values were normalized with respect to those obtained upon transfection of the reporter plasmid alone. (B) Stimulation of Tat-dependent activation in HeLa cells by wild-type, but not mutated PITALRE. Transfection assays with (+) or without $(-)$ a Tat expression vector are indicated.
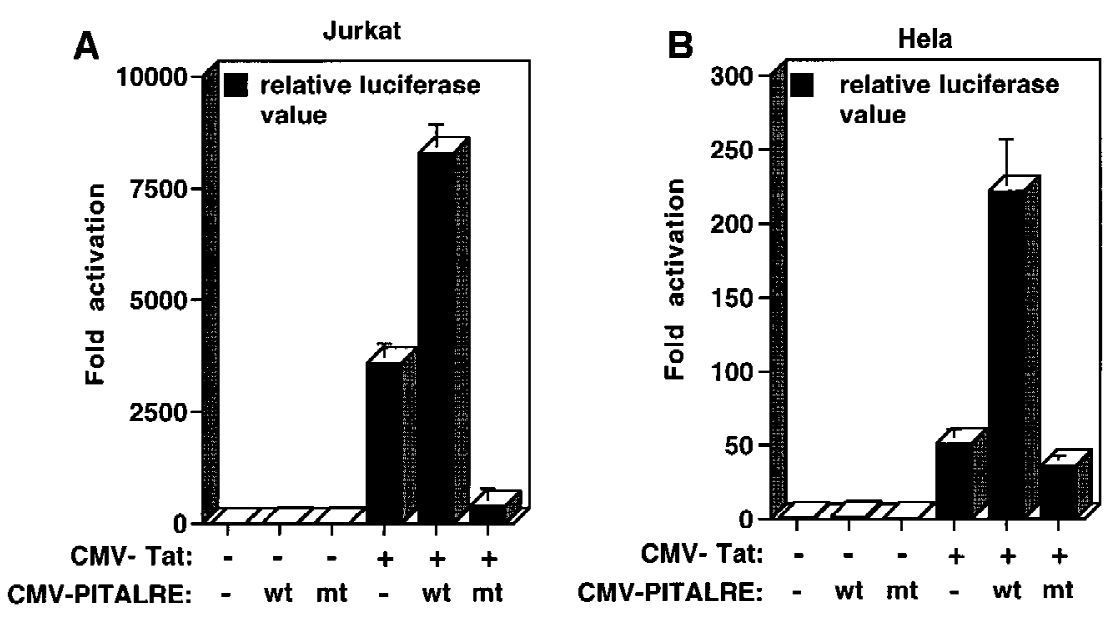
P-TEFb is required for Tat function. In fact, we believe that there are several as yet unidentified factors that are required for Tat-dependent transcriptional activation. Several lines of evidence support this hypothesis. First, purified P-TEFb does not function as a T at cofactor on its own, but, rather, requires other activities present in the depleted extract to reveal its ability to augment Tat transactivation (Fig. 5C). Furthermore, fractionation of nuclear extracts has led to the identification of a chromatographic fraction that is required in addition to $\mathrm{P}-\mathrm{TEFb}$ for Tat transactivation. In the presence of P-TEFb, this activity inhibits selectively the formation of promoter-distal transcripts and has no effect on the formation of promoter-proximal RNA products. In the presence of this chromatographic fraction, Tat-dependent activation of transcription results from the antirepression of transcriptional elongation $(\mathrm{H}$. M ancebo and O. Flores, unpubl.).

Direct evidence of a role for P-TEFb in Tat activation in vivo is provided by transient transfection experiments in Jurkat and HeLa cells with either the wild-type PITALRE subunit or one containing a null mutation (Fig. 6). Tat-independent transcription from the HIV LTR was equival ent whether or not the PITALRE gene carried the null mutation. In the presence of the wild-type, but not the mutated PITALRE gene, Tat-activated transcription was stimulated consistently in both cell types, indicating that transcriptional enhancement is dependent on the enzymatic activity of the wild-type gene. In addition, these results suggest strongly that the entry of P-TEFb into the transcription cycle is dependent on Tat. Additional evidence for a role of P-TEFb in Tat activation derived from the observation that the kinase mutant effectively inhibited Tat-dependent transcription (Fig. $6 \mathrm{~A}, \mathrm{~B})$.

It has been shown that stimulation of transcription elongation is not an exclusive property of Tat, but is a general regulatory step in vivo (Yankulov et al. 1994). Moreover, existing evidence suggests that individual transcriptional activation domains have distinct intrinsic potentials to stimulate elongation processivity (Blau et al. 1996). These observations led to the speculation that activators employ various strategies to regulate the transition from abortive to productive el ongation. An obvious possibility is that multiple kinases promote productive elongation by acting on either the same or different substrates, and that different acti vators recruit different kinases. On this note, recent studies have implicated the IIH-associated kinase $\mathrm{Cdk} 7 / C y c l i n ~ \mathrm{H}$ in the stimulation of transcription elongation by DNA binding transcriptional activators (Yankulov et al. 1996) and by T at (Parada and Roeder 1996; Garcia-M artinez et al. 1997). Substantial evidence indicate that IIH and PTEFb act at different steps of the transcription reaction. It is believed that IIH is required for promoter clearance (Goodrich and Tjian 1994; A koulitchev et al. 1995) and that P-TEFb regulates the transition from abortive to processive elongation ( $M$ arshall et al. 1996). It is reasonable to speculate that both of these steps are temporally and mechanistically coupled and that Tat might coordi- nate both, promoter clearance via IIH and el ongation potential via P-TEFb. This study does not rule out the possible involvement of the IIH-associated kinase in Tat transactivation, but clearly indicates that the critical kinase in Tat function is P-TEFb.

Transcriptional activator proteins could al so stimulate elongation by directing the assembly of preinitiation complexes that are intrinsically more processive than those formed in the absence of an activator. This could be achieved by inhibiting the association of factors that inhibit elongation. This possibility is consistent with the observation that abortive el ongation is a general rate limiting step in gene transcription (Krumm et al. 1995). For example, Pol II el ongation complexes that are either formed in the absence of an elongation repressor or refractory to the action of a repressor would not require P-TEFb for productive el ongation.

It will be important to address directly whether P$T E F b$ is a general or promoter-specific el ongation factor, and whether kinases other than P-TEFb control the transition from abortive to productive el ongation in vivo. On the basis of currently existing evidence, P-TEFb is be lieved to be an el ongation factor required for the efficient expression of many but not all genes. We believe that P-TEFb and other general factors that support efficient LTR-specific transcription are not sufficient for activation by $T$ at and that $T$ at stimulates transcription by overcoming inhibition by a negative regulator of transcriptional elongation. Tat might relieve this el ongation block either by recruiting P-TEFb to the promoter or by inhibiting directly the function of factors that cause abortive el ongation, or both. The devel opment of a welldefined transcription system that recapitulates Tat transactivation with purified cofactors will be required to decipher the precise mechanism of Tat-dependent transcriptional activation. Characterization of the mechanisms of action of novel Tat inhibitors may facilitate the identification of additional cellular proteins required for Tat-dependent transcriptional elongation. Random screens for such inhibitors, like the one described herein, may ultimately uncover regulatory proteins that represent potential new targets for the development of novel HIV therapeutics.

\section{Materials and methods}

Chemical reagents

DRB was purchased from Sigma. T174557 (2-lodo-5,6-dibromo1- $\beta$-D-ribofuranosyl benzimidazole), T172298 (2-Chloro-5,6-dibromobenzimidazole), and T 172299 (2-lodo-4,5,6,7-tetrabromobenzimidazole) were synthesized at Tularik as described (Zou et al. 1996). TRB (4,5,6-Trichloro-1- $\beta$-D-ribofuranosylbenzimidazole) and T525636 (2-methyl-5,6-dichloro-1- $\beta$-D-ribofuranosylbenzimidazole) were obtained from Merck. T276339 (4,5-dihydro-8-(methylthio)isoxazolo[5,4-D ]benzo[c]thiophene-6-carboxamide) was purchased from Maybridge. T1163693 (4,5,6,7tetrachlorobenzotriazole) was purchased from Sigma Aldrich Rare Chemicals. H7 [1-(5-Isoquinolinylsulfonyl)-2-methylpiperazine], H8 (N -[2-(methylamino)ethyl]-5-isoquinolinesulfonamide), and HA1004 (N-[2-guanidinoethyl]-5-isoquinolinesulfonamide) were purchased from Cal biochem. 


\section{Protein purification procedures}

For in vitro transcription assays, Pol II (Superdex 200 fraction, $100 \mathrm{ng}$ ) was purified as described (Lu et al. 1991), except for the addition of a Superdex 200 (Pharmacia) fractionation step; HeLa nuclear extracts $(14 \mu \mathrm{g})$, TFIID (DE-52 fraction, $1.0 \mu \mathrm{g}$ ), TFIIA (DE-52 fraction, $5 \mu \mathrm{g}$ ), TFIIH (M ono $S$ fraction, $100 \mathrm{ng}$ ), recombinant Pol IIB, Pol IIE, and Pol IIF were all prepared as described (Reinberg et al. 1987; Ha et al. 1991; Peterson et al. 1991; Flores et al. 1992; Chang et al. 1993); HCMV IE2 and GAL4-VP16 were purified according to Lee et al. (1996); BZLF was a gift from $V$. Baichwal (Tularik, Inc.); HIV-1 Tat (86 amino acids) with a Streptavidin binding tag at its carboxyl terminus was expressed in Escherichia coli using a pET-23b expression vector. The recombinant Tat was purified from E. coli by binding to Streptavidin resin (PIERCE) and el ution with a buffer containing $1 \mathrm{~mm}$ d-Biotin.

Purification of HeLa P-TEFb was as follows: HeLa nuclear extracts were fractionated on a phosphocellulose (P11, Whatman) column that was equilibrated in buffer D (20 mM HEPES at $\mathrm{pH}$ 7.9, $0.2 \mathrm{~mm}$ EDTA, 20\% glycerol, $10 \mathrm{~mm} \beta$-mercaptoethanol) containing $300 \mathrm{~mm} \mathrm{KCl}$. Two consecutive elutions were performed with four column volumes each of buffer $\mathrm{D}$ containing $500 \mathrm{~mm} \mathrm{KCl}$ and $1 \mathrm{M} \mathrm{KCl}$, respectively. The majority ( $>90 \%)$ of the anti-PITALRE crossreacting material was eluted in the $500 \mathrm{~mm}$ step. The P11-500 mm fraction was dialyzed to $150 \mathrm{~mm}$ $\mathrm{KCl}$ and applied to a Mono Q column (HR10/10, Pharmacia) that was equilibrated with buffer $\mathrm{D}+150 \mathrm{~mm} \mathrm{KCl}$ and eluted with a linear gradient from $150-500 \mathrm{mM} \mathrm{KCl}$. Although a significant amount $(\sim 50 \%)$ of PITALRE was detected in the flowthrough, the DRB sensitive anti-PITALRE crossreacting material bound to and co-eluted from the Mono Q column. Active fractions were pooled, dialyzed to $150 \mathrm{mM} \mathrm{KCl}$, and bound to a second M ono Q column (HR10/10) that was stepeluted with buffer $\mathrm{D}+500 \mathrm{~mm} \mathrm{KCl}$. Fractions containing the bulk of the protein were pooled and loaded into a Sephacryl $\mathrm{S}-400$ column (400 ml, Pharmacia) that was equilibrated in buffer $\mathrm{D}+500 \mathrm{~mm} \mathrm{KCl}$. The elution volume (Ve) of PITALRE was $250 \mathrm{ml}$ (for comparison, the Ve of Pol IIH and Pol IID from $\mathrm{S}-400$ is 280 and $150 \mathrm{ml}$, respectively). Fractions containing anti-PITALRE crossreacting material were dialyzed to $100 \mathrm{~mm}$ $\mathrm{KCl}$ and loaded onto a M ono S column (HR5/5, Pharmacia) that was equilibrated in the same buffer. The column was devel oped with a 30-ml linear gradient from $100-400 \mathrm{~mm} \mathrm{KCl}$, and activity was eluted at $\sim 200 \mathrm{~mm} \mathrm{KCl}$. The pooled, active fractions were dialyzed to $100 \mathrm{~mm} \mathrm{KCl}$ and loaded onto a second M ono S column (HR5/5), which was step-eluted with buffer D +500 mm $\mathrm{KCl}$. Fractions containing the peak of protein were pooled and loaded directly into a Superdex 200 column (HR10/30, Pharmacia) equilibrated with buffer D +500 mM KCl. The Superdex 200 P-TEFb fraction was purified more than 3000-fold.

\section{Immunoprecipitation of P-TEFb}

HeLa cell nuclear extract $(10 \mathrm{mg})$ was diluted to $10 \mathrm{ml}$ with HM-200 solution (200 mM KCl, 0.5\% N P-40, 1\% Triton X-100, $20 \mathrm{~mm}$ HEPES at pH 7.9, 0.7\% $\beta$-mercaptoethanol). The extract was then incubated with polyclonal PITALRE antibodies (Santa Cruz) for $4 \mathrm{hr}$ at $4^{\circ} \mathrm{C}$, followed by additional 1-hr incubation with $400 \mu \mathrm{l}$ of protein A-agarose (Cal biochem). The beads were then washed five times with $\mathrm{HM}-1000$ solution $(1 \mathrm{M} \mathrm{KCl}, 0.5 \%$ N P-40, 1\% Triton X-100, 20 mM HEPES at pH 7.9, 0.7\% $\beta$-mercaptoethanol).

In vitro transcription assays

Reaction mixtures $(50 \mu \mathrm{l})$ contained $25 \mathrm{~mm}$ HEPES at $\mathrm{pH}$ 7.9,
$6 \%$ glycerol, $6 \mathrm{~mm} \mathrm{M} \mathrm{gCl}_{2}, 0.1 \mu \mathrm{g}$ poly(I-C) (Pharmacia), $5 \mathrm{~mm}$ $\mathrm{N} \mathrm{aCl}, 50 \mathrm{~mm} \mathrm{KCl}, 300 \mu \mathrm{M}$ each of ATP, GTP, and UTP, and 10 $\mu \mathrm{M}$ CTP (Pharmacia), $2 \mu \mathrm{Ci}\left[\alpha^{-32} \mathrm{P}\right] \mathrm{CTP}$ (NEN , $800 \mathrm{Ci} / \mathrm{mmole}$ ), and 5\% DMSO (Sigma). Reactions were assembled as follows. DNA template, nucleotides, and buffers were added first, followed by the addition of either an individual compound dissolved in DMSO or DMSO al one (control). The various proteins fractions were added last, and the reaction mixtures were incubated at room temperature for $45 \mathrm{~min}$. Reaction mixtures were then treated with 10 units RN ase T1 (Boehringer), $0.1 \mathrm{mg} / \mathrm{ml}$ of proteinase $K$ and reactions products separated in $6 \%$ polyacrylamide, $7 \mathrm{~m}$ urea gel s. A detailed protocol describing the mechanics of the medium throughput drug screening assay will be published elsewhere.

\section{RNase protection assays}

$\mathrm{RN}$ ase protection assays of label ed RN A products obtained from in vitro transcription reactions were performed as described (Ausubel et al. 1995), except that RNA samples were first treated with 2-3 units of DN ase I (Promega) for $25 \mathrm{~min}$ at $37^{\circ} \mathrm{C}$ and an excess ( 5 pmoles) of cold RN A probe was added to the assay. Protected fragments were separated on $6 \%$ polyacrylamide sequencing gels and visualized by autoradiography.

\section{Kinase assays}

The Pol IIH kinase reaction $(50 \mu \mathrm{l})$ contained $20 \mathrm{~mm}$ HEPES at $\mathrm{pH} 7.0,10 \mathrm{~mm} \mathrm{M} \mathrm{gCl} 2,5 \mathrm{~mm} \mathrm{M} \mathrm{nCl}, 0.2 \mu \mathrm{g} / \mu \mathrm{l}$ of bovine serum al bumin (BSA), $1 \mu \mathrm{M}$ ATP, 0.5 mM DTT, $2 \mu \mathrm{g}$ of 4XCTD peptide, and $2 \mu \mathrm{Ci}$ of $\left[\gamma^{-32} \mathrm{P}\right] \mathrm{ATP}$, and was carried out at $37^{\circ} \mathrm{C}$ for $30 \mathrm{~min}$. The Pol IIH kinase fraction was purified as described (Flores et al. 1992) and was free of P-TEFb, as indicated by Western blots with antibodies to PITALRE. The presence of C $\mathrm{dk} 7$ and Cyclin $\mathrm{H}$ in our Pol IIH preparation was confirmed by Western blot analyses.

The p34 and CKII kinase reactions contained in common 20 $\mathrm{mm}$ Tris at $\mathrm{pH} 7.5,50 \mathrm{mM} \mathrm{KCl}, 10 \mathrm{~mm} \mathrm{M} \mathrm{gCl} 2,50 \mu \mathrm{M} \mathrm{ZnCl}, 10$ $\mu \mathrm{M}$ ATP, and $1 \mathrm{~mm}$ DTT. In addition, the p34 assay contained 1 unit of p34 (NEB), $2 \mu \mathrm{g}$ histone $\mathrm{H} 1$ (Cal biochem), and $2.5 \mu \mathrm{Ci}$ [ $\gamma^{-32}$ P]ATP. The CKII assay contained 5 units of CKII (NEB), 2 $\mu \mathrm{g}$ casein (Sigma), and $7.5 \mu \mathrm{Ci}\left[\gamma^{-32} \mathrm{P}\right] \mathrm{ATP}$. Both the p34 and CKII assays were performed at $30^{\circ} \mathrm{C}$ for $30 \mathrm{~min}$, and the reactions were stopped with the addition of SDS gel loading buffer. Samples were then subjected to SDS-PAGE, and kinase activity was quantified by Phosphorlmager analysis.

p-TEFb kinase assays were performed as described by Zhu et al. (this issue) except that 5\% DMSO was present.

\section{Analyses of the effects of compounds in cell culture assays}

The cell-based Tat transactivation assay. A Jurkat cell line described previously (Byrnes and Hazuda 1996), which contains a stably integrated, defective HIV (HXB2) provirus bearing a mutation in the Tat initiation codon and a luciferase reporter gene replacement in the env gene, was grown in complete RPM I 1640 (GIBCO BRL) containing 10\% heat-inactivated calf serum, 2 mM L-gl utamine and penicillin/streptomycin. Cells were transfected with either a T at expression plasmid (pucD 5 T at), or with a control plasmid lacking T at, using the DEAE/D extran method (Byrnes and Hazuda 1996). Cells were aliquoted into 96-well plates at $9.0 \times 10^{4}$ cells/well and incubated for $22 \mathrm{hr}$ with or without varying amounts of test compounds in a final solvent (DMSO) concentration of $1 \%$. Luciferase activity was measured with the Promega luciferase assay system using a modified lysis 
buffer (Byrnes and Hazuda 1996), and activity was detected with a Dynatech microlite 1, 96-well plate luminometer (Dynatech).

\section{The cell-based CMV assay}

A Jurkat cell line containing a stably integrated CMV IE promoter $(-760$ to +7$)$ driving luciferase was constructed as de scribed for the above HIV reporter cell line (Byrnes and Hazuda 1996). Cells were grown in complete RPMI 1640 and then mock-transfected with the pucD5 control plasmid using the DEAE/dextran method, plated and treated with compounds as described for the Tat transactivation assay. Luciferase activity was measured as described above.

\section{The cytotoxicity assay}

The effect of each compound on cell proliferation was measured with the nonradioactive cell proliferation assay kit Cell Titer 96 AQueous (Promega, M adison, WI), which is a quantitative, MTS [3-(4,5-dimethlythiazol-2-yl)-5-(3-carboxymethoxyphenyl)-2-(4sulfophenyl)-2H-tetrazolium inner salt] colorimetric assay. The assay was performed in replicate plates in parallel with the cellbased HIV Tat and CMV transactivation assays. Briefly, test compound or solvent was added to the cells in 96-well plates as described above for the transactivation assays. At $22 \mathrm{hr}$ after addition of the compound, MTS [20 $\mu$, final concentration 333 $\mu \mathrm{g} / \mathrm{ml}$ in $25 \mathrm{~mm}$ phenazine methosulfate (PMS)] was added to wells containing $100 \mu \mathrm{l}$ of media, and the cells were incubated at $37^{\circ} \mathrm{C}$ in $5 \% \mathrm{CO}_{2}$ for $2 \mathrm{hr}$. A bsorbance at $490 \mathrm{~nm}$ was read with a M olecular Dynamics (UV max) plate reader. The percentage of control cells remaining after treatment with compound was determined rel ative to solvent-treated control cells. The assay was linear for the number of cells as assessed by the trypan blue exclusion method and absorbance at $490 \mathrm{~nm}$.

\section{Transient cotransfection assays}

Jurkat cells $\left(2 \times 10^{6}\right)$ grown to log phase were resuspended in serum-free RPMI, plated in 35-mm cell culture dishes, and transfected with lipofectamine (GIBCO BRL) in serum-free RPM I. Complete RPM I was added to the cells $12 \mathrm{hr}$ after transfection, and cells were harvested after $36 \mathrm{hr}$. Luciferase activity was measured as described above. Expression vectors were synthesized with pCDN A 3 (Promega) as the parent vector and used to drive the expression of Tat, wild-type PITALRE, and mutated PITALRE.

\section{Acknowledgments}

We thank Kelly LaM arco for her outstanding work in editing the manuscript and our colleagues at Tularik for helpful discussions. This work was supported in part by $\mathrm{N}$ ational Institutes of Health grant GM 35500 .

The publication costs of this article were defrayed in part by payment of page charges. This article must therefore be hereby marked "advertisement" in accordance with 18 USC section 1734 solely to indicate this fact.

\section{References}

Akoulitchev, S., T.P. Makela, R.A. Weinberg, and D. Reinberg. 1995. Requirement for IIH kinase activity in transcription by RN A polymerase II. Nature 377: 557-560.

Ausubel, F., R. Brent, R.E. Kingston, D. Moore, J.G. Seidman,
J.A. Smith, and K. Struhl. 1995. RN ase protection assay. In Current protocols in molecular biology. Vol. 1, pp. 4.7.14.7.8. Greene-Wiley, N ew York, NY.

Blau, J., H. Xiao, S. M cCracken, P. O'Hare, J. Greenblatt, and D. Bentley. 1996. Three functional classes of transcriptional activation domains. Mol. Cell. Biol. 16: 2044-2055.

Byrnes, V. and D. Hazuda. 1996. A system to analyze and identify inhibitors of HIV-1 gene regulation using a defective integrated provirus. Methods Enzymol. 275: 348-361.

Chang, C., C.F. Kostrub, and Z.F. Burton. 1993. RAP30/ 74 (transcription factor (IF) is required for promoter escape by RN A polymerase II. J. Biol. Chem. 268: 20482-20489.

Chodosh, L.A., A. Fire, M. Samuels, and P.A. Sharp. 1989. 5,6-Dichloro-1-beta-D-ribofuranosylbenzimidazole inhibits transcription elongation by RNA polymerase II in vitro. J. Biol. Chem. 264: 2250-2257.

Dahmus, M.E. 1996. Reversible phosphorylation of the C-terminal domain of RNA polymerase II. J. Biol. Chem. 271: 19009-19012.

Feinberg, M.B., D. Baltimore, and A.D. Frankel. 1991. The role of Tat in the human immunodeficiency virus life cycle indicates a primary effect on transcriptional el ongation. Proc. Natl. Acad. Sci. 88: 4045-4059.

Flores, O., H. Lu, and D. Reinberg. 1992. Factors involved in specific transcription by mammalian RNA polymerase II. Identification and characterization of factor $\mathrm{IIH}$. J. Biol. Chem. 267: 2786-2793.

Fraser, N.W., P.B. Sehgal, and D.E. Darnell, Jr. 1979. Multiple discrete sites for premature RNA chain termination late in adenovirus-2 infection: Enhancement by 5,6-dichloro-1beta-D-ribofuranosyl benzimidazole. Proc. Natl. Acad. Sci. 76: 2571-2575.

Garcia-M artinez, L.F., G. Mavankal, J.M. N eveu, W.S. Lane, D. Ivanov, and R.B. Gaynor. 1997. Purification of a Tat-associated kinase reveals a TFIIH complex that modulates HIV-1 transcription. EMBO J. 16: 2836-2850.

Goodrich, J.A. and R. Tjian. 1994. Transcription factors IIE and $\mathrm{IIH}$ and ATP hydrolysis direct promoter clearance by RNA polymerase II. Cell 77: 145-156.

Ha, I., W.S. Lane, and D. Reinberg. 1991. Cloning of a human gene encoding the general transcription initiation factor IIB. Nature 352: 689-695.

Herrmann, C.H. and A.P. Rice. 1993. Specific interaction of the human immunodeficiency virus Tat proteins with a cellular protein kinase. Virology 197: 601-608.

_-_. 1995. Lentivirus Tat proteins specifical ly associate with a cellular protein kinase, TAK, that hyperphosphorylates the carboxyl-terminal domain of the large subunit of RN A polymerase II: Candidate for a Tat cofactor. J. Virol. 69: 16121620.

Hsu, M.C., A.D. Schutt, M. Holly, L.W Slice, M.I. Sherman, D.D. Richman, M.J. Potash, and D.J. Volsky. 1992. Discovery and characterization of an HIV-1 Tat antagonist. Biochem. Soc. Trans. 20: 525-531.

Jones, K.A. and B.M. Peterlin. 1994. Control of RNA initiation and elongation at the HIV-1 promoter. Annu. Rev. Biochem. 63: 717-743.

Klucher, K.M., M. Sommer, J.T. Kadonaga, and D.H. Spector. 1993. In vivo and in vitro analysis of transcriptional activation mediated by the human cytomegal ovirus major immediate-early proteins. Mol. Cell. Biol. 13: 1238-1250.

Krumm, A., L.B. Hickey, and M. Groudine. 1995. Promoterproximal pausing of RNA polymerase II defines a general rate-limiting step after transcription initiation. Genes \& Dev. 9: 559-572.

Laspia, M.F., A.P. Rice, and M.B. Mathews. 1989. HIV-1 Tat 
protein increases transcriptional initiation and stabilizes elongation. Cell 59: 283-292.

- - 1 1990. Synergy between HIV-1 Tat and adenovirus E1A is principally due to stabilization of transcriptional el ongation. Genes \& Dev. 4: 2397-2408.

Laub, O., E.B. Jakobovits, and Y. Aloni. 1980. 5,6-dichloro-1beta-ribofuranosylbenzimidazole enhances premature termination of late transcription of Simian virus 40 DN A. Proc. Natl. Acad. Sci. 77: 3297-3301.

Lee, G., J. Wu, P. Luu, P. Ghazal, and O. Flores. 1996. Inhibition of the association of RNA polymerase II with the preinitiation complex by a viral transcriptional repressor. Proc. Natl. Acad. Sci. 93: 2570-2575.

Lu, H., O. Flores, R. Weinmann, and D. Reinberg. 1991. The nonphosphorylated form of RNA polymerase II preferentially associates with the preinitiation complex. Proc. Natl. Acad. Sci. 88: 10004-10008.

Marciniak, R.A. and P.A. Sharp. 1991. HIV-1 Tat protein promotes formation of more-processive elongation complexes. EMBO J. 10: 4189-4196.

Marciniak, R.A., B.J. Calnan, A.D. Frankel, and P.A. Sharp. 1990. HIV-1 Tat protein trans-activates transcription in vitro. Cell 63: 791-802.

Marshall, N .F., J. Peng, Z. Xie, and D.H. Price. 1996. Control of RNA polymerase Il el ongation potential by a novel carboxylterminal domain kinase. J. Biol. Chem. 271: 27176-27183.

Michne, W.F., J.D. Schroeder, T.R. Bailey, H.C. Neumann, D. Cooke, D.C. Young, J.V. Hughes, S.D. Kingsley, K.A. Ryan, H.S. Putz et al. 1995. Keto/enol epoxy steroids as HIV-1 Tat inhibitors: Structure-activity relationships and pharmacophore localization. J. Med. Chem. 38: 3197-3206.

Newstein, M., E.J. Stanbridge, G. Casey, and P.R. Shank. 1990. Human chromosome 12 encodes a species-specific factor which increases human immunodeficiency virus type 1 Tatmediated transactivation in rodent cells. J. Virol. 64: 45654567.

Parada, C.A. and R.G. Roeder. 1996. Enhanced processivity of RN A polymerase II triggered by Tat-induced phosphorylation of its carboxy-terminal domain. Nature 384: 375-378.

Peterson, M.G., J. Inostroza, M.E. Maxon, O. Flores, A. Admon, D. Reinberg, and R. Tjian. 1991. Structure and functional properties of human general transcription factor IIE. Nature 354: 369-373.

Reinberg, D., M. Horikoshi, and R.G. Roeder. 1987. Factors involved in specific transcription in mammalian RNA polymerase II. Functional analysis of initiation factors IIA and IID and identification of a new factor operating at sequences downstream of the initiation site. J. Biol. Chem. 262: 33223330.

Sheline, C.T., L.H. Milocco, and K.A. Jones. 1991. Two distinct nuclear transcription factors recognize loop and bulge residues of the HIV-1 TAR RNA hairpin. Genes \& Dev. 5: 25082520.

Tamm, I. and T. Kikuchi. 1979. Early termination of heterogeneous nuclear RNA transcripts in mammalian cells: Accentuation by 5,6-dichloro-1-beta-D-ribofuranosylbenzimidazole. Proc. Natl. Acad. Sci. 76: 5750-5754.

Tweeten, K.A. and G.R. Molloy. 1981. Induction of premature termination of transcription of the mouse beta-globin gene by 5,6-dichloro-1-beta-D-ribofuranosyl benzimidazole (DRB). Nucleic Acids Res. 9: 3307-3319.

Winslow, B.J. and D. Trono. 1993. The blocks to human immunodeficiency virus type $1 \mathrm{~T}$ at and Rev functions in mouse cell lines are independent. J. Virol. 67: 2349-2354.

Yang, X., C.H. Herrmann, and A.P. Rice. 1996. The human immunodeficiency virus Tat proteins specifically associate with TAK in vivo and require the carboxyl-terminal domain of RNA polymerase II for function. J. Virol. 70: 4576-4584.

Yankulov, K., J. Blau, T. Purton, S. Roberts, and D.L. Bentley. 1994. Transcriptional elongation by RNA polymerase II is stimulated by transactivators. Cell 77: 749-759.

Yankulov, K.Y., M. Pandes, S. McCracken, D. Bouchard, and D.L. Bentley. 1996. TFIIH functions in regulating transcriptional el ongation by RN A polymerase II in Xenopus oocytes. Mol. Cell. Biol. 16: 3291-3299.

Zandomeni, R. and R. Weinmann. 1984. Inhibitory effect of 5,6-dichloro-1-beta-D-ribofuranosyl benzimidazole on a protein kinase. J. Biol. Chem. 259: 14804-14811.

Zandomeni, R., M.C. Zandomeni, D. Shugar, and R. Weinmann. 1986. Casein kinase type II is involved in the inhibition by 5,6-dichloro-1-beta-D-ribofuranosylbenzimidazole of specific RNA polymerase II transcription. J. Biol. Chem. 261: 3414-3419.

Zhou, Q. and P.A. Sharp. 1995. N ovel mechanism and factor for regulation by HIV-1 Tat. EMBO J. 14: 321-328.

-_- 1996. Tat-SF1: Cofactor for stimulation of transcriptional el ongation by HIV-1 Tat. Science 274: 605-610.

Zhu, Y., T. Pe'ery, J. Peng, Y. Ramanathan, N. Marshall, T. Marshall, B. Amendt, M.B. Mathews, and D.H. Price. 1997. Transcription el ongation factor P-TEFb is required for HIV-1 Tat transactivation in vitro. Genes \& Dev. (this issue).

Zou, R., K.R. Ayres, J.C. Drach, and L.B Townsend. 1996. Synthesis and antiviral evaluation of certain disubstituted benzimidazole ribonucleosides. J. Med. Chem. 39: 3477-3482. 


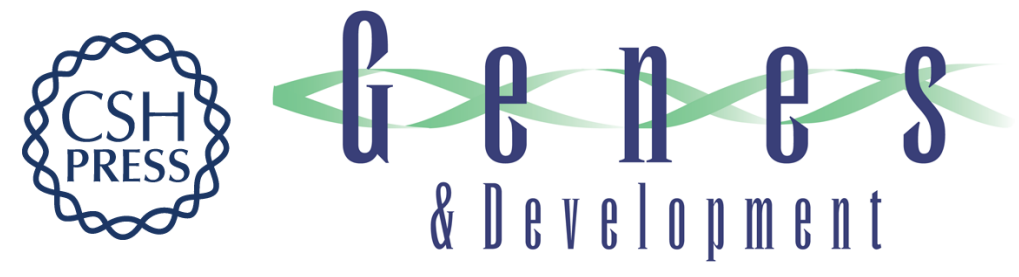

\section{P-TEFb kinase is required for HIV Tat transcriptional activation in vivo and in vitro}

Helena S.Y. Mancebo, Gary Lee, John Flygare, et al.

Genes Dev. 1997, 11:

Access the most recent version at doi:10.1101/gad.11.20.2633

References

This article cites 43 articles, 27 of which can be accessed free at: http://genesdev.cshlp.org/content/11/20/2633.full.html\#ref-list-1

\section{License}

Email Alerting

Receive free email alerts when new articles cite this article - sign up in the box at the top Service right corner of the article or click here.

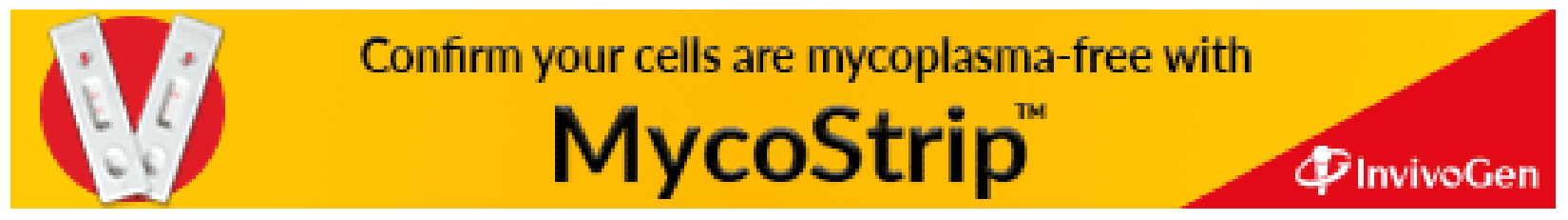

